\title{
Endoscopic ultrasound for localisation of islet cell tumours
}

\author{
J R Glover, P J Shorvon, W R Lees
}

\begin{abstract}
In a prospective study endoscopic ultrasound localisation of pancreatic endocrine tumours was attempted in 21 patients with clinically suspected islet cell tumours. Most patients were referred after the failure of conventional imaging methods. Endoscopic ultrasound correctly identified the site of 12 of $\mathbf{1 5}$ insulinomas, one glucagonoma, and a diffuse pancreatic abnormality in a patient with multiple endocrine adenopathy. There were two true negative examinations and one technical failure. The sensitivity of endoscopic ultrasound was much greater than that of computed tomography or conventional transabdominal ultrasonography.
\end{abstract}

Pancreatic endocrine tumours have well described characteristic clinical presentations, ${ }^{12}$ but, as there is only limited success with medical management, surgery is usually necessary. Although islet cell tumours are often palpable at surgery, ${ }^{3} 10 \%$ of the insulinomas and $60 \%$ of gastrinomas may be multiple or malignant. Therefore, preoperative localisation is desirable to reduce the duration and complexity of the operation. However, the visualisation of functioning pancreatic islet cell tumours has been problematic for most conventional imaging modalities because the lesions are generally small, ${ }^{4}$ and they are located in an organ to which there is limited access. Whereas there are enthusiasts for localisation by computed tomography, ${ }^{56}$ conventional ultrasound, ${ }^{78}$ angiography, ${ }^{9}$ venous sampling, ${ }^{10}{ }^{11}$ and more recently peroperative ultrasound, ${ }^{37-912-14}$ none of these has achieved overall predominance, and reported success rates have not always been reproduced in other centres. ${ }^{15}{ }^{16}$ Endoscopic ultrasound allows the positioning of a high frequency ultrasound transducer in close proximity to the whole length of the pancreas without intervening abdominal wall and bowel to consistently produce high resolution images of the gland.

This study was set up to test the ability of the technique to demonstrate and localise islet cell tumours.

Patients and methods

All the patients were referred for endoscopic

TABLE I Insulinoma patients

\begin{tabular}{|c|c|c|c|c|c|c|c|c|c|c|c|c|}
\hline $\begin{array}{l}\text { Patient } \\
\text { No }\end{array}$ & Sex & $\begin{array}{l}\text { Age } \\
\text { (years) }\end{array}$ & $\begin{array}{l}\text { Size of } \\
\text { tumour } \\
(\mathrm{mm})\end{array}$ & $\begin{array}{l}\text { Endoscopic } \\
\text { ultrasound }\end{array}$ & Ultrasound & $\begin{array}{l}\text { Computed } \\
\text { tomography }\end{array}$ & Angiography & $\begin{array}{l}\text { Venous } \\
\text { sampling }\end{array}$ & Other ${ }^{\star}$ & Histology & Site & Comments \\
\hline 1 & $\mathbf{F}$ & 76 & 15 & + & - & - & 0 & 0 & & + & Uncinate & \\
\hline 2 & $\mathbf{F}$ & 45 & 11 & + & - & - & - & 0 & [1] & + & Neck & \\
\hline 3 & $M$ & 23 & 40 & - & - & - & 0 & 0 & [2] & + & Head & \\
\hline 4 & $\mathrm{~F}$ & 16 & 10 & - & - & - & - & - & [-] & + & Splenic hilum & \\
\hline 5 & $\mathbf{F}$ & 70 & 35 & + & - & - & 0 & 0 & & + & Head & \\
\hline 6 & $\mathbf{M}$ & 35 & 15 & + & - & - & 0 & 0 & & + & Tail & \\
\hline 7 & M & 55 & 27,15 & $+/+$ & $+1-$ & $+1-$ & 0 & 0 & [3] & + & Neck and body & Two lesions \\
\hline 8 & M & 69 & 7 & + & - & - & 0 & 0 & & 0 & Head & Patient died, no necropsy \\
\hline 9 & $\mathbf{M}$ & 76 & 15 & + & - & - & 0 & 0 & & + & Tail & $\begin{array}{l}\text { Computed tomography+ } \\
\text { retrospectively }\end{array}$ \\
\hline 10 & $\mathbf{F}$ & 41 & 10 & + & + & + & 0 & 0 & & + & Head & \\
\hline 11 & $\mathbf{M}$ & 62 & 11 & + & - & - & - & 0 & & + & Uncinate & $\begin{array}{l}\text { Angiography located lesion in } \\
\text { head }\end{array}$ \\
\hline 12 & M & 60 & 8 & - & - & - & 0 & 0 & & + & Splenic hilum & $\begin{array}{l}\text { Endoscopic ultrasound showed } \\
\text { reactive node in body }\end{array}$ \\
\hline 13 & $\mathbf{F}$ & 54 & 6 & + & - & + & 0 & 0 & & 0 & Neck & Not found surgery or at necropsy \\
\hline 14 & $M$ & 73 & 6 & + & - & - & $\overline{0}$ & 0 & & + & Body & \\
\hline 15 & $\mathbf{M}$ & 49 & 20 & + & - & - & 0 & 0 & & + & Neck & \\
\hline 16 & $\mathbf{F}$ & 31 & 8 & + & - & - & - & - & & + & Body & \\
\hline
\end{tabular}

$\star 1=$ magnetic resonance imaging also negative; 2 =previous partial pancreatectomy. Computed tomography and angiography showed the lesion at the splenic hilum but it was interpreted as a splenunculus; $3=$ both shown in percutaneous pancreatogram.

$+=$ true positive; $-=$ negative; $0=$ not performed.

TABLE II Non-insulinoma patients

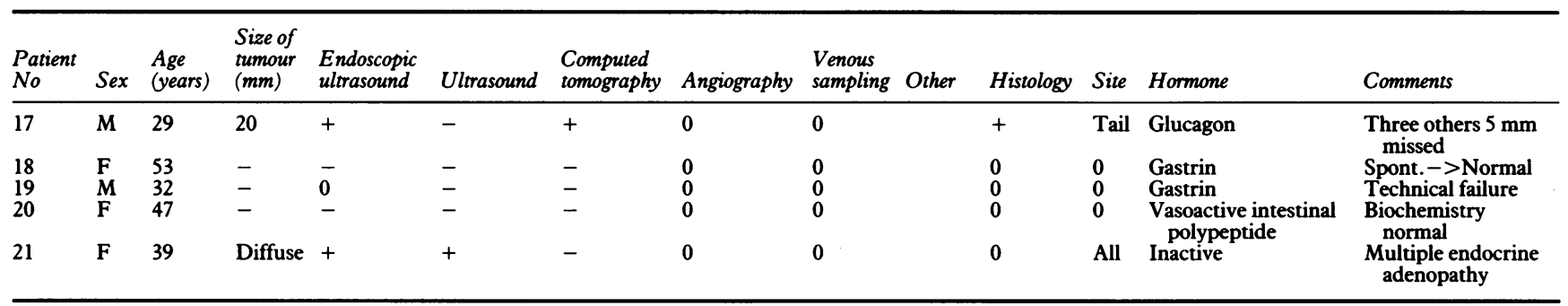


TABLE III Endoscopic ultrasound $\mathrm{v}$ other investigations (insulinomas)

\begin{tabular}{llllll}
\hline & Angiography & $\begin{array}{l}\text { Computed } \\
\text { tomography }\end{array}$ & Ultrasound & $\begin{array}{l}\text { Venous } \\
\text { sampling }\end{array}$ & $\begin{array}{l}\text { Endoscopic } \\
\text { ultrasound }\end{array}$ \\
\hline No of patients & 5 & 14 & 14 & 2 & 14 \\
True positive & 0 & 3 & 2 & 0 & 11 \\
False positive & 1 & 0 & 0 & 0 & 1 \\
Sensitivity & 0 & $21 \%$ & $14 \%$ & 0 & $79 \%$ \\
\hline
\end{tabular}

^Lesion incorrectly identified as insulinoma.

ultrasound imaging of the pancreas from this and other hospitals over a 30 month period. Most referrals were due to failure of other imaging techniques. All patients had biochemical evidence or there was a strong clinical suspicion of islet cell tumours. Sixteen patients had biochemical evidence of insulinomas (Table I), two had suspected gastrinomas, and one each suspected glucagonoma, vipoma, and multiple endocrine adenopathy (Table II). Ten patients were women and 11 were men, mean age 49 years (range 16-76 years). All had previously been investigated by a minimum of high resolution computed tomography and conventional transabdominal ultrasound. The endoscopic ultrasound probe used has a $7.5 \mathrm{MHz}$ rotating transducer attached to the end of a side viewing endoscope (Olympus GF-UM2 Ultrasonic Endoscope, Keymed, Southend, UK). The transducer rotates at 10 revolutions per second producing a realtime $360^{\circ}$ radial image at right angles to the long axis of the endoscope. It is passed down to the duodenal loop under direct vision after intravenous sedation and nasopharyngeal local anaesthesia, as for conventional endoscopy. Once in the descending duodenal loop air is sucked out of the bowel and a balloon covering the transducer is distended with water to facilitate maximum contact and acoustic coupling with the mucosa. The endoscope with attached transducer is then slowly withdrawn through the duodenum, pylorus, and stomach to the oesophageal hiatus, stopping at any suspicious lesions for careful local scanning, measurement, and accurate localisation of the lesion. This can easily be repeated if necessary. After recovery from the sedation patients were discharged the same day, unless their underlying clinical state required continued hospitalisation or admission. The procedure took 10-30 minutes and was no more uncomfortable for patients than conventional fibreoptic gastroduodenoscopy.

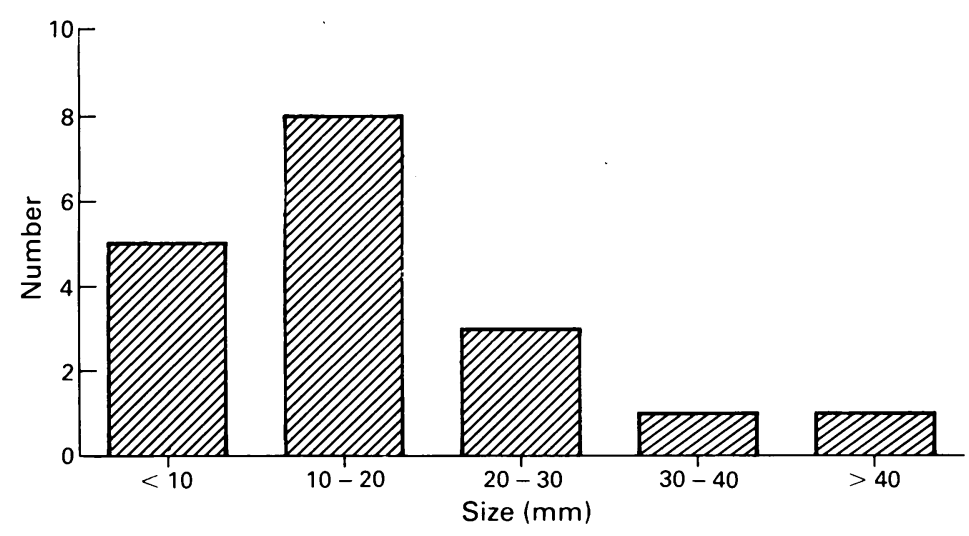

Figure 1: Size distribution of insulinomas.

\section{Results}

Of the 16 patients with biochemically suspected insulinomas, positive histology was obtained in 14 (Table I). There was no predilection for any single site in the pancreas. One patient with convincing biochemical evidence of insulinoma died of fulminating pancreatitis after surgery at which no tumour could be found, and no lesion was identified at subsequent necropsy, although endoscopic ultrasound had shown a $6 \mathrm{~mm}$ lesion in the neck of the pancreas (case 13). Another patient died without surgery and necropsy was refused (case 8 ). There were 15 tumours in the remaining 14 insulinoma patients, 12 of which were correctly identified and localised by endoscopic ultrasound. The three lesions missed consisted of a $40 \times 15 \mathrm{~mm}$ lesion in the head, subsequently identified by intraoperative ultrasound, and two lesions in the splenic hilum. One of these was in a patient who had had a distal pancreatectomy. Of the remaining five patients, there was one technical failure due to duodenal scarring which prevented passage of the scope beyond the pylorus in a patient with the Zollinger-Ellison syndrome (case 19). There were two true negatives, one in a patient with suspected gastrinoma in whom the levels subsequently spontaneously returned to normal, and one in a patient with symptoms of a recurrent vipoma in whom blood levels of vasoactive intestinal polypeptide consistently remained normal. One patient had a $20 \mathrm{~mm}$ glucagonoma shown on endoscopic ultrasound but three further $5 \mathrm{~mm}$ lesions were also found at surgery which were not shown by endoscopic ultrasound. The patient with multiple endocrine adenopathy syndrome was shown to have a diffusely abnormal pancreas with multiple small tumours.

Conventional ultrasound detected only two islet cell tumours, and showed diffuse pancreatic abnormality in the patient with multiple endocrine adenopathy type 1 . Computed tomography identified three insulinomas and showed the $20 \mathrm{~mm}$ glucagonoma.

The site of five lesions was suspected on conventional imaging before endoscopic ultrasound. No adverse effects were noted in any of the patients after endoscopic ultrasound.

\section{Discussion}

Most patients in this series were referred for endoscopic ultrasound because of the failure of other imaging modalities, which is reflected in the very low sensitivities of computed tomography (25\%) and ultrasound (18\%) (Table III) compared with other series..$^{5-8}$ Most of the lesions were less than $19 \mathrm{~mm}$ and five were less than 9 mm (Fig 1).

Some investigators advocate computed tomography and selective angiography for preoperative localisation of pancreatic endocrine tumours, ${ }^{6}$ but angiography is more invasive than endoscopic ultrasound and has a greater risk of adverse events. In this series six of the insulinoma patients were investigated by angiography and computed tomography but none of the lesions was correctly located, and one of the lesions (case 11) was localised to the head rather 


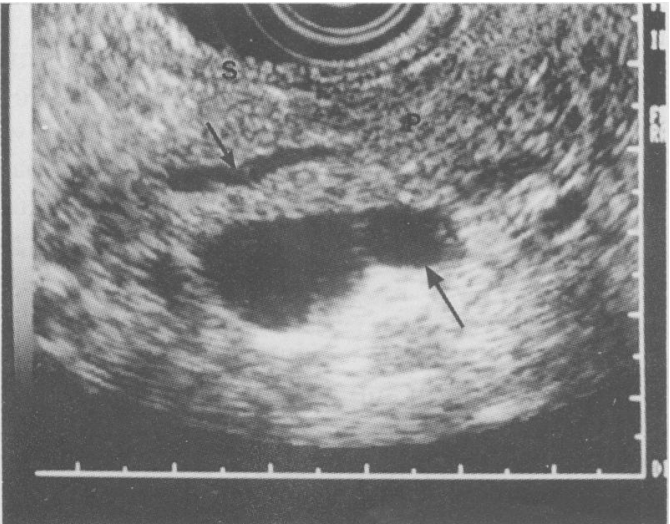

Figure 2: Transverse section through the body of the pancreas showing normal pancreatic tissue $(P)$ and duct (small arrow) in front of splenic vein (large arrow). $S=$ stomach wall.

than the uncinate lobe and could not be found at subsequent laparotomy performed before endoscopic ultrasound.

Endoscopic ultrasound is safe and noninvasive compared with angiography and venous sampling. The depth of penetration of the ultrasound beam is limited to approximately $6 \mathrm{~cm}$ from the transducer, and it produces radial images which require experience to orientate and interpret (Fig 2). Islet cell tumours generally appear as well circumscribed lesions, hypoechoic compared with the surrounding normal pancreas (Fig 3).

A proven alternative is peroperative ultrasound scanning after full mobilisation of the pancreas. In recent reports peroperative ultrasound combined with surgical palpation has produced a sensitivity of up to $100 \% .{ }^{814}$ Peroperative scanning may lead the surgeon directly to the lesion but it prolongs surgery and requires a confident preoperative diagnosis which is often difficult to achieve. Localisation by endoscopic ultrasound can greatly reduce the extent of surgical mobilisation required and size of resection. Ultrasonic endoscopes are wider than simple side viewing scopes, with a longer nonflexible tip which can make entry into the duodenum difficult, especially if there is scarring (see case 19). However, future ultrasonic endoscopes are likely to be narrower and more flexible. As well as showing pancreatic lesions as small as $6 \mathrm{~mm}$, endoscopic ultrasound also shows the bowel wall with great accuracy, which is important in gastrinoma patients whose lesions may be in the duodenal wall. Endoscopic ultrasound may have a blind spot in the region of the splenic hilum but so may other imaging modalities, as case 2 shows.

We believe that endoscopic ultrasound is a useful adjunct to the investigation and localisation of islet cell tumours, which will replace other more invasive techniques, and we recom-

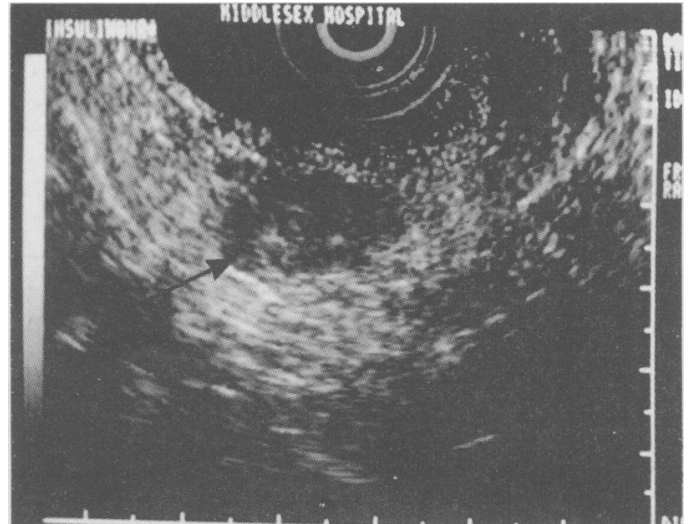

Figure 3: Well circumscribed insulinoma (arrowed) in the tail of the pancreas showing a complex internal low level echo pattern.

mend it as the next investigation after computed tomography and ultrasound. As pancreatic endocrine tumours may be small and multiple it should be performed in all such patients or small functioning lesions may be missed, particularly if they coexist with larger lesions visible with other modalities.

1 Turner RC. Hypoglycaemia. In: Wetherall DJ, Ledingham JGG, Warell, DA, eds. Oxford textbook of medicine. 2nd ed. Oxford: Oxford Medical Publications, 1987: 9.102-8.

2 Bloom SR, Long RG, Polak JMO. Hormones and the gastrointestinal tract. In: Wetherall DJ, Ledingham JGG, Warell DA, eds. Oxford textbook of medicine. 2nd ed. Oxford: Oxford Medical Publications, 1987: 12.52-61.

3 Harrison TS. The hypoglycemic syndrome, endogenous hyperinsulinism. In: Friesen SR, Bolinger RE, eds. Surgical endocrinology. Philadelphia: JB Lippincott, 1978: 150-9.

4 Grant CS, van Heerden JA, Charboneau JW, et al. Insulinoma - the value of intraoperative ultrasonography. Arch Surg - the value of in

5 Wank SA, Doppman JL, Miller DL, et al. Prospective study of the ability of computed axial tomography to localize gastrinomas in patients with Zollinger-Ellison syndrome. Gastroenterology 1987; 92: 905-12.

6 Rossi P, Allison DJ, Bezzi M, et al. Endocrine tumors of the pancreas. Radiol Clin North Am 1989; 27: 129 61.

7 Gorman B, Charboneau JW, James EM, et al. Benign pancreatic insulinoma: preoperative and intraoperative localization. $A \mathcal{F R} 1986$; 147: 929-34.

8 Galiber AK, Reading CC, Charboneau JW, et al. Localization of pancreatic insulinoma: comparison of pre- and intraoperative US with CT and angiography. Radiology 1988; 166: to5-8.

9 Gianello P, Gigot JF, Berthet F, et al. Pre- and intraoperative localization of insulinomas: report of 22 observations. World localization of insulinom

10 Doppman JL, Brennan MF, Dunnick NR, et al. The role of pancreatic venous sampling in the localization of occult insulinomas. Radiology 1981; 138: 557-62

11 Parkman HP, Malet PF, Ogorek CP, et al. Preoperative localization of a vasoactive intestinal peptide-secreting tumor by transhepatic portal venous sampling. $A m \mathcal{F}$ Gastroenterol 1988; 83: 559-63.

12 Sigel B, Duarte B, Coelho JCU, et al. Localization of insulinomas of the pancreas at operation by real-time ultrasound scanning. Surg Gynecol Obstet 1983; 156:145-7.

13 Charboneau JW, James EM, van Heerden JA, et al. Intraoperative real-time ultrasonographic localization of pancreatic insulino

14 Norton JA, Cromack DT, Shawker TH, et al. Intraoperative ultrasonographic localization of islet cell tumours - a prospective comparison to palpation. Ann Surg 1988; 207: 160-8.

15 Frucht H, Doppman JL, Norton JA, et al. Gastrinomas: comparison of MR imaging with CT, angiography, and US Radiology 1989; 171: 713-7. 